\title{
Clinical and radiological findings of incidental Rathke's cleft cysts in children and adolescents
}

Yeon Joung Oh, $\mathrm{MD}^{1}$, Hong Kyu Park, MD', Seung Yang, MD', Jun Ho Song, MD', II Tae Hwang, MD ${ }^{1}$

Departments of ${ }^{1}$ Pediatrics and ${ }^{2}$ Neurosurgery, Hallym University College of Medicine, Seoul, Korea
Purpose: In the pediatric population, Rathke's cleft cysts (RCCs) are known to be an infrequent cause of headaches, visual disturbances, and pituitary dysfunction. We investigated the clinical characteristics of children in whom RCCs were incidentally discovered and evaluated whether RCCs influence the treatment response of patients with proven endocrinopathy.

Methods: A retrospective analysis was conducted in 34 patients with RCCs who were diagnosed between 2006 and 2013 at Hallym University Medical Center. Their clinical, hormonal, and imaging findings were reviewed. We evaluated the clinical outcomes of the patients with concomitant RCCs and endocrinopathy compared to matched controls.

Results: Twenty-six of 34 patients with radiologically proven RCCs had endocrine disorders. They were 9 boys and 17 girls, with ages ranging from 4.8 to 17.4 years at the time of the diagnosis. Of these, 7 (27\%) had idiopathic short stature, $7(27 \%)$ had growth hormone deficiency (GHD), and $12(46 \%)$ had central precocious puberty (CPP). Nineteen of 26 patients (73.1\%) showed low signal intensities on T1-weighted images (T1WI) and high signal intensities on T2-weighted images. The incidence of hypointensity on T1WI was higher in the patients with RCCs accompanied by endocrinopathy than in those without endocrinopathy $(P=0.033)$. The treatment outcomes of the patients with CPP and GHD with and without RCCs were similar. Conclusion: CPP and GHD patients with a small RCC (less than $20 \mathrm{~mm}$ ) expressing cystic magnetic resonance intensity can be managed with medical treatment, although the RCCs need to be closely monitored in radiological studies to observe their growth.

Keywords: Central nervous system cysts, Pituitary dwarfism, Precocious puberty, Central

\section{Introduction}

Rathke's cleft cysts (RCCs) are nonneoplastic sellar lesions derived from remnants of the embryonic Rathke's pouch ${ }^{11}$. Rathke's pouch normally closes in early fetal development, but failure of this pouch to regress upon formation of adenophysis and neurophysis can result in an $\mathrm{RCC}^{2}$. They develop as cystic lesions located between the anterior and posterior lobes of the pituitary gland and are discovered intra and/or suprasellar lesions ${ }^{3)}$. RCCs are often clinically silent throughout life. According to a postmortem examination of 1,000 unselected autopsy specimens, 113 pituitary glands (11.3\%) harbored incidental RCCs ${ }^{4}$. As RCCs increase in size slowly with time, they may become clinically evident later in life. Typical symptoms are headaches, visual disturbances, and endocrinological dysfunction. However, as shown in a case study, there may be severe clinical consequences, such as pituitary apoplexy and aseptic meningitis ${ }^{5}$. Although the prevalence of RCCs in adults is rather high, reported in up to $22 \%$ of subjects in routine autopsies, RCCs in children are rarer. In addition, most

Tel: +82-2-2224-2251

Fax: +82-2-482-8334

E-mail: ithwang83@hallym.or.kr 
remain asymptomatic as determined by autopsy and magnetic resonance imaging (MRI) studies, and the asymptomatic RCCs that are identified in children are typically smaller than those found in adults ${ }^{4,6-8)}$.

With growing public interest in child growth and development and widespread availability of MRI, pediatric endocrinologists are expected to see increasing numbers of patients with radiological diagnosis of RCCs. Although there are many studies on the manifestations and prognosis of RCCs, most of the data are derived from case series of adult patients, and there are little data describing the presentation and outcome of RCCs in children. Several cases of RCCs were reported in a pediatric population, but the numbers of patients were small (Table 1) ${ }^{9-14)}$. Thus far, the natural history and optimal treatment strategy for RCCs in children have not been clearly specified, especially in pediatric patients with endocrine disorders associated with growth delay. Given the relatively low likelihood of improvement and potential for worsened pituitary function after surgery, surgical intervention might not be a good option in this specific population if there are no evident symptoms due to mass effect of the cyst on adjacent structures such as visual loss or persistent headaches ${ }^{12)}$.

In the present study, we retrospectively analyzed children and adolescents with concomitant RCCs and endocrinopathy. The aims of our study were to investigate (1) the clinical characteristics of the children and adolescents with endocrine disorders in whom RCCs were incidentally identified, (2) the radiological characteristics of their RCCs as compared to RCC patients without endocrine dysfunction, and (3) the potential influence of RCCs on the treatment response of the patients with proven endocrine disorders.

\section{Materials and methods}

\section{Patients}

From January 2006 to August 2013, a total of 34 cases of
RCCs were identified in children and adolescents aged from 4 to 18 years at Hallym University Medical Center. All the RCCs were diagnosed by brain MRI. Of these 34 RCCs, five were discovered in patients who presented with headache or dizziness and three in patients with febrile convulsion or head trauma. Twenty-six RCCs (76.4\%) were discovered during evaluations for endocrine disorders. All the patients received standard medical treatment, and none of them underwent a surgical intervention due to the RCC.

\section{Acquisition and analysis of clinical and radiological data}

The medical records of the patients were retrospectively reviewed after receiving approval from our Institutional Review Board. We obtained information regarding the history, physical examination, age, sex, height, weight, bone age (BA), and sexual maturity rating from the medical records of the patients. Height standard deviation score (SDS) and weight SDS adjusted for chronological age (CA) were calculated using the 2007 growth reference for Korean children and adolescents. The BA was assessed according to the Greulich and Pyle method, and sexual maturation was classified according to the Marshall and Tanner method. Midparental height (MPH) was calculated as follow: [paternal height $(\mathrm{cm})+$ maternal height $(\mathrm{cm})] / 2+6.5 \mathrm{~cm}$ (boys), or $-6.5 \mathrm{~cm}$ (girls). MPH SDS was calculated using average height and standard deviation of adults aged 20. The diagnosis of endocrine disorders was based on the clinical presentations, as well as laboratory and radiological evidence. The endocrine disorders were classified into three types: central precocious puberty (CPP), growth hormone deficiency (GHD), and idiopathic short stature (ISS).

Serological examination of the patient's endocrine dysfunction included measurement of basal thyroid stimulating hormone, free thyroxin, insulin-like growth factor-I, insulin-like growth factor binding protein-3, prolactin, adrenocorticotropic hormone, cortisol, luteinizing hormone ( $\mathrm{LH})$, follicular stimulating hormone, testosterone, and estradiol and electrolyte

Table 1. Summary of prior reports of RCCs in pediatric patients

\begin{tabular}{|c|c|c|c|c|c|c|c|c|c|}
\hline \multirow[b]{2}{*}{ Author (yr) } & \multirow[b]{2}{*}{$\begin{array}{c}\text { No. of } \\
\text { patients }\end{array}$} & \multirow{2}{*}{$\begin{array}{l}\text { Age (yr), } \\
\text { median } \\
\text { (range) }\end{array}$} & \multicolumn{5}{|c|}{ Clinical presentation at the time of diagnosis } & \multirow{2}{*}{$\begin{array}{c}\text { - Cystic size (mm), } \\
\text { median (range) }\end{array}$} & \multirow[b]{2}{*}{ Treatment } \\
\hline & & & Headache (\%) & $\begin{array}{c}\text { Visual } \\
\text { disturbance (\%) }\end{array}$ & GHD (\%) & CPP (\%) & Other $^{a)}(\%)$ & & \\
\hline $\begin{array}{l}\text { Jahangiri, et al.9. } \\
\text { (2011) }\end{array}$ & 14 & $16.0(3.0-18.0)$ & 50.0 & 7.1 & 45.4 & 0 & 7.1 & $12.0(7.0-20.0)$ & All surgical \\
\hline $\begin{array}{l}\text { Lim and Yang }^{10)} \\
(2010)\end{array}$ & 44 & $10.1(0.1-18.2)$ & 45.6 & 13.6 & NR & 18.2 & 25.0 & $N R$ & $\begin{array}{c}\text { Surgical (65.9\%), } \\
\text { CTx (34.1\%) }\end{array}$ \\
\hline $\begin{array}{l}\text { Katavetin et al. }{ }^{11)} \\
(2010)\end{array}$ & 13 & $14.0(12.0-17.0)$ & 84.6 & 15.4 & 0 & 7.7 & 23.1 & $12.2(7.0-15.0)$ & $\begin{array}{c}\text { Surgical (30.8\%), } \\
\operatorname{CTx}(69.2 \%)\end{array}$ \\
\hline $\begin{array}{l}\text { Zada et al. }{ }^{12)} \\
(2009)\end{array}$ & 10 & $13.0(2.0-17.0)$ & 70.0 & 10.0 & 30.0 & 0 & 40.0 & $13.6(8.0-18.0)$ & All surgical \\
\hline $\begin{array}{l}\text { Frazier et al. } \\
\text { (2008) }\end{array}$ & 1 & 14.0 (NA) & 100 & 0 & 0 & 0 & 0 & 30.0 (NA) & All surgical \\
\hline $\begin{array}{l}\text { Kim et al. } \\
(2004)\end{array}$ & 1 & 11.0 (NA) & 100 & 100 & 0 & 0 & 0 & 16.0 (NA) & All surgical \\
\hline
\end{tabular}

GHD, growth hormone deficiency; CPP, central precocious puberty; NA, not applicable; CTx, conservative treatment

${ }^{\text {a) }}$ Other endocrine disorder. 
levels. In selected cases, a growth hormone $(\mathrm{GH})$ provocation test and a gonadotropin releasing hormone $(\mathrm{GnRH})$ stimulation test were also performed. The inclusion criteria for GHD were a stature more than two standard deviations (SD) below the mean or less than the 3 rd percentile for the same age and gender, a growth velocity of less than $4 \mathrm{~cm} / \mathrm{yr}$, and a peak GH level below $10 \mathrm{ng} / \mathrm{mL}$ in two $\mathrm{GH}$ stimulation tests using clonidine, insulin, or L-dopa. The criteria for ISS included patients whose height was more than two SD below the corresponding average height for a given age and sex, without findings of disease, and who had a peak GH level above $10 \mathrm{ng} / \mathrm{mL}$ in $\mathrm{GH}$ stimulation test. The clinical and hormonal criteria for CPP were onset of the development of pubertal characteristics before 8 years in girls and 9 years in boys and a pubertal response of LH to a standard GnRH stimulation test ( $\mathrm{LH}$ peak $\geq 5 \mathrm{mIU} / \mathrm{mL}$ ).

All RCCs were proven by brain MRI, and radiological characteristics, such as the size, the location, and the signal intensities of the cysts on T1- and T2-weighted images, were reviewed and analyzed by two or more radiologists. We analyzed MR signal intensities in 26 patients with RCCs in whom concomitant endocrine disorders compared to that in 8 patients without concomitant endocrine disorders.

\section{Analysis of clinical outcome after 1 year of treatment}

To analyze the clinical outcomes after medical treatment for 1 year, the patients with concomitant RCC and CPP or GHD were 1-to-2 matched. The patients with CPP received treatment with a GnRH agonist (leuprolide-acetate or triptorelin) $100 \mu \mathrm{g} / \mathrm{kg}$ every 4 weeks. The patients with GHD were given subcutaneous injections of recombinant human growth hormone (hGH) at a dose of $0.5-0.7 \mathrm{IU} / \mathrm{kg} / \mathrm{wk}$. We evaluated the patients' heights, weights, and BA and the results of a hormonal assay before and 12 months after treatment. The clinical outcome measures were defined as follows: (1) basal LH level, change in height SDS and disparity between BA and CA in the CPP group and (2) change in height SDS and height velocity (the difference in height before and 1 year after treatment, $\mathrm{cm} / \mathrm{yr}$ ) in the GHD group. The patients with ISS were excluded in this analysis because the treatment response to $\mathrm{GH}$ would vary considerably.

\section{Statistical analysis}

All statistical analyses were performed using SPSS ver. 16.0 (SPSS Inc., Chicago, IL, USA). Continuous variables were presented as the means \pm standard deviation and were compared

Table 2. Baseline characteristics of patients with RCCs

\begin{tabular}{|c|c|c|c|c|c|}
\hline Characteristic & ISS $(n=7)$ & GHD $(n=7)$ & CPP $(n=12)$ & Others $(n=8)$ & Overall $(n=34)$ \\
\hline Age (yr) & $10.1 \pm 4.1$ & $10.7 \pm 3.0$ & $8.4 \pm 2.2$ & $11.02 \pm 4.9$ & $9.7 \pm 3.6$ \\
\hline Male/female & $4 / 3$ & $3 / 4$ & $4 / 8$ & $6 / 2$ & $17 / 17$ \\
\hline Height (cm) & $122.6 \pm 22.0$ & $123.9 \pm 15.6$ & $134.7 \pm 15.6$ & $142.9 \pm 28.0$ & $132.2 \pm 21.2$ \\
\hline Weight (kg) & $27.9 \pm 15.2$ & $27.1 \pm 10.6$ & $37.4 \pm 1.5$ & $40.7 \pm 15.5$ & $34.3 \pm 13.8$ \\
\hline Body mass index $\left(\mathrm{kg} / \mathrm{m}^{2}\right)$ & $17.3 \pm 2.5$ & $17.1 \pm 3.9$ & $20.1 \pm 2.6$ & $19.2 \pm 3.3$ & $18.8 \pm 3.3$ \\
\hline Bone age & $8.5 \pm 4.4$ & $7.6 \pm 2.8$ & $10.8 \pm 2.4$ & - & - \\
\hline Height SDS & $-2.6 \pm 0.9$ & $-2.4 \pm 0.3$ & $1.3 \pm 0.9$ & $0.2 \pm 1.2$ & $-0.5 \pm 1.9$ \\
\hline Weight SDS & $-1.7 \pm 0.8$ & $-1.8 \pm 1.4$ & $1.4 \pm 0.7$ & $0.0 \pm 0.0$ & $-0.2 \pm 1.6$ \\
\hline $\mathrm{MPH}(\mathrm{cm})$ & $160.1 \pm 7.9$ & $163.9 \pm 7.4$ & $164.1 \pm 9.6$ & - & - \\
\hline MPH SDS & $-1.5 \pm 0.5$ & $-0.6 \pm 0.8$ & $-0.2 \pm 1.0$ & - & - \\
\hline Tanner stage $|/||/|||$ & $5 / 0 / 2$ & $5 / 2 / 0$ & 0/8/4 & - & - \\
\hline \multicolumn{6}{|c|}{ Radiological features of patients' RCCs } \\
\hline Size $(\mathrm{mm})$ & $3.6 \pm 2.3$ & $8.0 \pm 6.5$ & $5.5 \pm 5.0$ & $9.2 \pm 5.2$ & $6.2 \pm 5.0$ \\
\hline$<10$ & $7(100)$ & $4(54.1)$ & $10(83.3)$ & $5(62.5)$ & $26(76.5)$ \\
\hline $10-20$ & $0(0)$ & $3(45.9)$ & $2(16.7)$ & $3(37.5)$ & $8(23.7)$ \\
\hline \multicolumn{6}{|l|}{ Location } \\
\hline Pas intermedia & 6 & 6 & 12 & 8 & 32 \\
\hline Anterior lobe & 1 & 1 & 0 & 0 & 2 \\
\hline \multicolumn{6}{|l|}{ T1 signal intensity } \\
\hline Low & 6 & 5 & 9 & 3 & 23 \\
\hline Iso & 1 & 2 & 3 & 4 & 10 \\
\hline High & 0 & 0 & 0 & 1 & 1 \\
\hline \multicolumn{6}{|l|}{ T2 signal intensity } \\
\hline Low & 1 & 1 & 2 & 6 & 10 \\
\hline Iso & 0 & 1 & 0 & 0 & 1 \\
\hline High & 6 & 5 & 10 & 2 & 23 \\
\hline
\end{tabular}

Values are presented as mean \pm standard deviation or number (\%).

RCC, Rathke's cleft cyst; ISS, idiopathic short stature; GHD, growth hormone deficiency; CPP, central precocious puberty; SDS, standard deviation score; MPH, midparental height. 
using the Student $t$-test. Categorical variables were compared using the chi-square test or Fisher exact test, as appropriate.

Propensity score matching was performed to avoid selection bias and potential confounding in a retrospective study. The following variables were selected to calculate the propensity score by binary logistic regression: age, gender, height, weight, and body mass index. The cohort was paired with a nearest neighbor (1:2 match) cohort using the calculated score of the nearest available pairs from a registry consisting of 150 children and adolescents diagnosed with CPP or GHD but not RCC. The propensity score matching procedure yielded 34 well-matched pairs: 20 children with CPP and 14 children with GHD, respectively. After the propensity score matching, baseline covariates were compared between the patients with RCCs and the controls. A paired $t$-test was used to assess the treatment response in each subject, and differences in the clinical outcomes between the patients and matched controls were analyzed using an independent $t$-test. A $P$-value $<0.05$ was considered statistically significant.

\section{Results}

\section{Baseline clinical characteristics and radiological feature of RCCs}

The baseline demographic data and the radiological characteristics of the RCCs on MRI are listed in Table 2. Among 26 patients with radiologically proven RCCs, there were nine boys and 17 girls, with ages ranging from 4.8 to 17.4 years at the time of diagnosis. They consisted of 7 ISS patients (27\%), 7 GHD patients (27\%), and $12 \mathrm{CPP}$ patients (46\%). The CPP group showed female dominant feature $(66.7 \%)$ consistent with the epidemiological nature of the disease, whereas the other disease groups showed a balanced gender ratio. Pituitary hormone deficiency except $\mathrm{GH}$ was not discovered in all patients.

All the cysts were purely intrasellar. Twenty-four were located in pas intermedia, and two were located in the anterior lobe. The diameter of none of the RCCs exceeded $20 \mathrm{~mm}$, and most were less than $10 \mathrm{~mm}$ in size (ranging from 1 to $17 \mathrm{~mm}$ ). The symptoms of five patients with headaches and dizziness spontaneously resolved or improved with medication, and none of our cohort underwent surgical treatment.

\section{MR signal intensity patterns of RCCs in the patients with endocrine disorders}

Nineteen of 26 patients (73.1\%) showed decreased signal intensities on the T1-weighted images and increased signal intensities on the T2-weighted images (Table 3). The remainder showed a high proportion of cerebrospinal fluid-like signal intensity patterns and a heterogeneous MR pattern, but none of the RCCs in the patients with endocrinopathy showed hyperintensity on the T1-weighted images. There was no intergroup difference in the prevalence of this cystic MR pattern among the ISS, GHD, and CPP groups (ISS vs. GHD vs. CPP, $5 / 7$ (71.4\%) vs. $5 / 7$ (71.4\%) vs. $9 / 12$ (75\%); $P=$ not significant). However, the incidence of this cystic MR pattern in the patients with RCCs accompanied by endocrinopathy was significantly higher than that in those without endocrine disorders $(P=0.033)$ (Table 4).

\section{Clinical outcomes of patients with CPP after 1 year of $\mathrm{GnRH}$ agonist treatment}

Compared to the matched controls, the baseline covariates of the CPP group were not different at the time of diagnosis, except the basal LH level (Table 5). After treatment for 1 year, a significant improvement was observed in breast development

\begin{tabular}{|c|c|c|c|}
\hline \multirow[b]{2}{*}{ Group } & \multicolumn{2}{|c|}{ Signal intensity patterns of RCCs, n (\%) } & \multirow[b]{2}{*}{$P$-value } \\
\hline & $\begin{array}{l}\text { Cystic MR pattern } \\
\text { (T1-hypo/T2-hyper) }\end{array}$ & $\begin{array}{c}\text { Noncystic MR pattern } \\
\text { (other than T1-hypo/T2-hyper) }\end{array}$ & \\
\hline I & $19(73.1)$ & $7(26.9)$ & \\
\hline$\|$ & $2(25.0)$ & $6(75.0)$ & 0.033 \\
\hline
\end{tabular}

MR, magnetic resonance; RCC, Rathke's cleft cyst; group I, the patients with RCCs in whom concomitant endocrine disorders were identified; group II, the patients without concomitant endocrine disorders.

Table 3. Signal intensity characteristics of RCCs on T1- and T2-weighted MR images according to groups

\begin{tabular}{|c|c|c|c|c|c|}
\hline \multirow{2}{*}{ Group } & \multirow{2}{*}{ T2-weighted image } & \multicolumn{3}{|c|}{ T1-weighted image, n (\%) } & \multirow{2}{*}{$P$-value } \\
\hline & & Hypointense & Isointense & Hyperintense & \\
\hline \multirow[t]{3}{*}{1} & Hypointense & $1(3.8)$ & $3(11.5)$ & $0(0)$ & \\
\hline & Isointense & $0(0)$ & $1(3.8)$ & $0(0)$ & \\
\hline & Hyperintense & $19(73.0)$ & $2(7.7)$ & $0(0)$ & $0.079^{\mathrm{a})}$ \\
\hline \multirow[t]{3}{*}{$\|$} & Hypointense & $1(12.5)$ & $4(50)$ & $1(12.5)$ & \\
\hline & Isointense & $0(0)$ & $0(0)$ & $0(0)$ & \\
\hline & Hyperintense & $2(25.0)$ & $0(0)$ & $0(0)$ & $0.007^{b)}$ \\
\hline
\end{tabular}

RCC, Rathke's cleft cyst; MR, magnetic resonance; group I, the patients with RCCs in whom concomitant endocrine disorders were identified; group II, the patients without concomitant endocrine disorders.

The $P$-value was expressed as the ${ }^{a)}$ statistical significance of the hypointense signal and the hyper- or iso-intense signal on the $T 1$ weighted image and the ${ }^{\text {b) }}$ statistical significance of the hyperintense signal and the iso- or hypointense signal on the T2-weighted image according to the groups. Statistical analysis was performed using Fisher exact test. 
compared to baseline in both groups. The BA increased slowly and the disparity between BA and CA became narrower in both groups compared to a year earlier $(P<0.05)$, and there was no significant difference in the clinical improvement between the study group and the control group. In both groups, height SDS remained unchanged compared to baseline. And no significant difference in the height SDS were observed between the patient and control group (Table 5). Basal LH levels were significantly decreased at the 1-year follow-up laboratory examination in the study group, but there were no significant differences in basal LH levels after treatment between the study and the control group. A follow-up MRI scan performed in nine of 12 patients (75\%) 1 year after the initial diagnosis revealed no change in the size of the cysts size or in the MR signal intensity pattern.

\section{Treatment outcomes 1 year after treatment with hGH in patients with GHD}

The distributions of observed baseline covariates were similar between the GHD group and the matched controls (Table 5). After treatment for 1 year, the height velocity was above $8 \mathrm{~cm} / \mathrm{yr}$ and the height SDS was increased significantly in both groups compared to 1 year earlier $(P<0.05)$. There was no significant difference observed in the height SDS and the height velocity between the two groups (Table 5). Five patients (71\%) were followed by brain MRI, and the cysts remained unchanged in size in all the patients.

\section{Discussion}

In the present study, we evaluated the clinical characteristic of 26 children and adolescents, recruited from four tertiary hospitals, with endocrine disorders in whom RCCs were incidentally discovered and radiological features of their RCCs. Our patients had small, intrasellar RCCs (less than 20 $\mathrm{mm})$, mostly of a cystic nature, on T1- and T2-weighted MRI (73.1\%), and the prevalence of this MR pattern was significantly higher than in the RCC subjects without endocrinopathy. After treatment for 1 year, the treatment outcomes were similar compared to the matched controls.

Data from adult patients demonstrated that most RCCrelated adenohypophyseal dysfunction, particularly panhypopituitarism, frequently fails to improve after surgical drainage, with a reported resolution rate of $14 \%$ to $20 \%$, and that the response to surgery tends to vary according to the subtype of endocrinopathy ${ }^{14-17)}$. In contrast, the majority of patients

Table 5. Comparison of the clinical parameters and outcomes between the patients with endocrine disorders and the matched controls before and 1 year after the treatment

\begin{tabular}{|c|c|c|c|c|c|c|}
\hline Variable & CPP & Control & P-value & GHD & Control & $P$-value \\
\hline \multicolumn{7}{|l|}{ At diagnosis } \\
\hline Male/female, n (\%) & $12(4 / 8)$ & $20(6 / 14)$ & & $7(3 / 4)$ & $14(6 / 8)$ & \\
\hline Age (yr) & $8.4 \pm 2.2$ & $8.9 \pm 0.8$ & NS & $10.3 \pm 3.2$ & $10.2 \pm 2.7$ & NS \\
\hline Height (cm) & $134.7 \pm 15.6$ & $137.0 \pm 6.8$ & NS & $123.9 \pm 15.6$ & $123.8 \pm 14.7$ & NS \\
\hline Weight (kg) & $37.41 \pm 1.5$ & $38.1 \pm 9.1$ & NS & $27.1 \pm 10.6$ & $25.9 \pm 11.3$ & NS \\
\hline BMI $\left(\mathrm{kg} / \mathrm{m}^{2}\right)$ & $20.1 \pm 2.6$ & $20.0 \pm 3.2$ & NS & $17.1 \pm 3.9$ & $16.3 \pm 3.5$ & NS \\
\hline Tanner stage |/II/II| & $0 / 8 / 4$ & $0 / 15 / 5$ & NS & $5 / 2 / 0$ & 10/5/0 & NS \\
\hline $\mathrm{BA}(\mathrm{yr})$ & $10.8 \pm 2.4$ & $10.9 \pm 0.8$ & NS & $7.6 \pm 2.8$ & $8.1 \pm 3.0$ & NS \\
\hline $\mathrm{BA}-\mathrm{CA}(\mathrm{yr})$ & $2.4 \pm 1.0$ & $2.1 \pm 0.7$ & NS & $-2.8 \pm 1.1$ & $-2.1 \pm 0.7$ & NS \\
\hline Height SDS & $1.3 \pm 1.0$ & $1.1 \pm 0.9$ & NS & $-2.4 \pm 0.3$ & $-2.4 \pm 0.4$ & NS \\
\hline Weight SDS & $1.4 \pm 0.7$ & $1.2 \pm 1.0$ & NS & $-1.8 \pm 1.4$ & $-2.0 \pm 0.9$ & NS \\
\hline Basal LH (mIU/mL) & $2.1 \pm 1.7$ & $1.0 \pm 0.8$ & 0.048 & - & - & - \\
\hline Peak LH (mlU/mL) & $15.9 \pm 13.2$ & $12.1 \pm 9.9$ & NS & - & - & - \\
\hline Peak FSH (mIU/mL) & $20.3 \pm 1.2$ & $17.1 \pm 4.2$ & NS & - & - & - \\
\hline Peak GH (ng/mL) & - & - & & $5.8 \pm 2.8$ & $4.8 \pm 2.8$ & NS \\
\hline GH dose (IU/kg/wk) & - & - & & $0.7 \pm 0.1$ & $0.7 \pm 0.1$ & NS \\
\hline \multicolumn{7}{|l|}{1 Year after treatment } \\
\hline Age (yr) & $9.4 \pm 2.2^{a)}$ & $9.9 \pm 0.7^{\text {a) }}$ & NS & $11.2 \pm 3.1^{\mathrm{a})}$ & $11.2 \pm 2.7^{\mathrm{a})}$ & NS \\
\hline $\mathrm{BA}-\mathrm{CA}(\mathrm{yr})$ & $1.8 \pm 0.9^{a)}$ & $1.3 \pm 0.8^{\mathrm{a})}$ & NS & $-2.4 \pm 1.6$ & $-2.0 \pm 0.9$ & NS \\
\hline Height SDS & $1.1 \pm 1.0$ & $1.1 \pm 0.9$ & NS & $-1.9 \pm 0.4^{\mathrm{a})}$ & $-1.8 \pm 0.3^{\mathrm{a})}$ & NS \\
\hline Weight SDS & $1.2 \pm 0.7^{\mathrm{a})}$ & $1.2 \pm 1.1$ & NS & $-1.8 \pm 1.3$ & $-1.6 \pm 0.9^{\mathrm{a})}$ & NS \\
\hline Basal LH (mIU/mL) & $0.7 \pm 0.8^{\mathrm{a})}$ & $0.8 \pm 0.4$ & NS & - & - & - \\
\hline $\mathrm{HV}(\mathrm{cm} / \mathrm{yr})$ & - & - & - & $8.0 \pm 2.4$ & $8.9 \pm 2.2$ & NS \\
\hline
\end{tabular}

Values are presented as mean \pm standard deviation unless otherwise indicated.

CPP, central precocious puberty; GHD, growth hormone deficiency; NS, not significant; BMI, body mass index; BA, bone age; CA, chronological age; SDS, standard deviation score; LH, luteinizing hormone; FSH, follicular stimulating hormone; GH, growth hormone; HV, height velocity.

${ }^{a} P<0.05$ compared with the same parameter at the time of diagnosis. 
with headaches or visual disturbances experienced an improvement ${ }^{14-17)}$. Likewise, recent case series of surgically treated pediatric RCCs also showed that pituitary dysfunction was not resolved in the majority of patients (Table 1) (9-14) $^{\text {. }}$ According to the reports, headaches and visual disturbances were more easily resolved by surgery, but some endocrine disorders were not. Moreover, most patients with CPP could be treated with medical treatment. In Korea, two studies describing the presentation and outcome of RCCs in children were published. In one study, a pediatric patient with surgically treated RCC presented with headaches and visual dysfunction ${ }^{14}$. Lim and Yang ${ }^{10)}$ found that RCCs were responsible for pituitary disorders and that GHD and diabetes insipidus did not improve after surgical intervention, although hyperprolactinemia resolved in all patients. They also reported that some endocrine disorders developed after the surgery. In general, children with ISS exhibit a normal GH secretion pattern in response to a $\mathrm{GH}$ stimulation test, but GH neurosecretory dysfunction may result in reduced spontaneous 24 hours GH secretion ${ }^{18,19)}$. Although data on RCCs with concomitant ISS are lacking, our results showed that the size and MR patterns of RCCs accompanied by ISS were similar to the RCCs in other endocrine disorders (CPP and GHD). There have been controversies on which symptoms are related to RCC. Large RCCs accompanied by persistent headaches or temporal visual field defects are generally accepted as an indication for surgical intervention. However, the relationship between RCCs and endocrine disorders, especially specific subtypes, such as CPP and GHD, has not been established yet.

In some cases, GHD with concomitant RCC can be improved by surgical removal of the RCC. However, according to a few studies, the resolution rate was relatively low following surgery. Aho et al. ${ }^{20)}$ reported that an improvement was seen in 14 of 78 patients (18\%) with GHD after removal of an RCC. In pediatric cases, symptoms of GHD were resolved in one of three patients with RCCs and concomitant GHD after surgery ${ }^{12)}$. In our study, all the patients with GHD were treated with $\mathrm{hGH}$, and their clinical outcomes were similar to those of the control group, without any change in the cysts. In addition, recent case reports of RCCs with concomitant CPP suggested that they improved following treatment with either a GnRH agonist or conservative treatment alone ${ }^{10,11,21)}$. Considering the high prevalence of subjects harboring incidental RCCs, the low rate of recovery from endocrine dysfunction after surgery, and the potential for improvement without surgical drainage, the argument about the correlation between symptoms and RCCs has remained unresolved. Regardless of the true association between them, we revealed that RCCs in patients with concomitant GHD and CPP could be treated nonsurgically and that their clinical outcome was similar to those without RCCs.

As shown previously, the signal intensity of RCCs on MR images varies considerably, depending on the cystic contents ${ }^{22)}$. Although no characteristic MRI features have been identified, many RCCs can be classified into one of the following two groups: RCCs with T1 hypointense/T2 hyperintense signals or
RCCs with a high signal intensity on T1-weighted images and a variable signal intensity on T2-weighted images. Nishioka et al. ${ }^{23)}$ found that adenohypophyseal dysfunction was associated with hyper- or iso-signal intensity on T1-weighted MR images rather than cyst size. The high protein or the mucus content within RCCs is believed to induce a tissue inflammatory response, and such stimulation participates in the development of symptoms, even in the case of small RCCs ${ }^{24)}$. On the other hand, RCCs with cerebrospinal fluid-like signal intensity are thought to grow slowly and not to cause clinical symptoms until they become large $e^{25)}$.

In our study, the cysts were all small, and no hyperintense T1 signal was observed in any of the cases. The equivalent treatment outcome of the study group and the control group might be due to the rather homogenous and unique MR pattern of our cohorts. Nevertheless, the six patients (26.9\%) with RCCs that showed an iso-intense signal on the T1-weighted images all had a similar outcome (data not shown). Most RCCs were intrasellar lesions on the MR image, and they were slow growing. Larger RCCs can become suprasellar lesions. According to studies conducted among 151 RCC patients who were surgically managed, RCCs with a suprasella component more commonly presented with visual dysfunction and were associated with higher postoperative endocrine morbidity ${ }^{26}$. The RCCs in our patients were all intrasellar lesions, and most of the patients did not present with visual symptoms.

Our study has several limitations, which include its retrospective nature and the sample size, which is small, although it represents one of the largest series of pediatric RCCs to date. The small sample size likely reflects the rarity of RCCs in this population. In addition, a follow-up MRI scan was not performed in all the cohorts, and pathological confirmation of the RCCs could not be made. Although MRI cannot make a definitive distinction between pathological entities, the diagnosis of a RCC is commonly confirmed with MRI in daily clinical practice. In our study, RCCs were differentiated from other cystic tumor by the imaging features and the location of the cystic lesion and were confirmed by two or more radiological specialists. Finally, the follow-up duration was relatively short. However, during the follow-up period, no patient needed surgical intervention.

The findings from our series containing exclusively prepubertal/pubertal cohorts with endocrinopathies suggest that CPP and GHD patients with a small RCC (less than $20 \mathrm{~mm}$ ) expressing cystic MR intensity can be managed with medical treatment. We believe that our findings provide valuable information for understanding the nature of pediatric RCCs and for developing an individualized therapeutic strategy. However, it is still unclear whether this specific population would have a positive clinical outcome during an extended follow-up period or whether RCCs with different MR signal intensity patterns would show similar outcomes. To answer these questions, welldesigned, large scale, prospective clinical trials are warranted.

\section{Conflict of interest}


No potential conflict of interest relevant to this article was reported.

\section{References}

1. Esiri M. Russell and Rubinstein's pathology of tumors of the nervous system. Sixth edition. J Neurol Neurosurg Psychiatry 2000;68:538D.

2. Raper DM, Besser M. Clinical features, management and recurrence of symptomatic Rathke's cleft cyst. J Clin Neurosci 2009; 16:385-9.

3. Voelker JL, Campbell RL, Muller J. Clinical, radiographic, and pathological features of symptomatic Rathke's cleft cysts. J Neurosurg 1991;74:535-44.

4. Teramoto A, Hirakawa K, Sanno N, Osamura Y. Incidental pituitary lesions in 1,000 unselected autopsy specimens. Radiology 1994;193:161-4.

5. Trifanescu R, Ansorge O, Wass JA, Grossman AB, Karavitaki N. Rathke's cleft cysts. Clin Endocrinol (Oxf) 2012;76:15160 .

6. Bayoumi ML. Rathke's cleft and its cysts. Edinb Med J 1948;55:745-9.

7. Shanklin WM. The incidence and distribution of cilia in the human pituitary with a description of microfollicular cysts derived from Rathke's cleft. Acta Anat (Basel) 1951;11:36182.

8. Takanashi J, Tada H, Barkovich AJ, Saeki N, Kohno Y. Pituitary cysts in childhood evaluated by MR imaging. AJNR Am J Neuroradiol 2005;26:2144-7.

9. Jahangiri A, Molinaro AM, Tarapore PE, Blevins L Jr, Auguste KI, Gupta N, et al. Rathke cleft cysts in pediatric patients: presentation, surgical management, and postoperative outcomes. Neurosurg Focus 2011;31:E3.

10. Lim HH, Yang SW. Risk factor for pituitary dysfunction in children and adolescents with Rathke's cleft cysts. Korean J Pediatr 2010;53:759-65.

11. Katavetin P, Cheunsuchon P, Grant E, Boepple PA, HedleyWhyte ET, Misra M, et al. Rathke's cleft cysts in children and adolescents: association with female puberty. J Pediatr Endocrinol Metab 2010;23:1175-80.

12. Zada G, Ditty B, McNatt SA, McComb JG, Krieger MD. Surgical treatment of rathke cleft cysts in children. Neurosurgery 2009;64:1132-7; author reply 1037-8.

13. Frazier JL, Chaichana K, Jallo GI, Quinones-Hinojosa A. Combined endoscopic and microscopic management of pediatric pituitary region tumors through one nostril: technical note with case illustrations. Childs Nerv Syst
2008;24:1469-78.

14. Kim JE, Kim JH, Kim OL, Paek SH, Kim DG, Chi JG, et al. Surgical treatment of symptomatic Rathke cleft cysts: clinical features and results with special attention to recurrence. J Neurosurg 2004;100:33-40.

15. Eguchi K, Uozumi T, Arita K, Kurisu K, Yano T, Sumida M, et al. Pituitary function in patients with Rathke's cleft cyst: significance of surgical management. Endocr J 1994;41:53540.

16. el-Mahdy W, Powell M. Transsphenoidal management of 28 symptomatic Rathke's cleft cysts, with special reference to visual and hormonal recovery. Neurosurgery 1998;42:716.

17. Kasperbauer JL, Orvidas LJ, Atkinson JL, Abboud CF. Rathke cleft cyst: diagnostic and therapeutic considerations. Laryngoscope 2002;112:1836-9.

18. Pedicelli S, Peschiaroli E, Violi E, Cianfarani S. Controversies in the definition and treatment of idiopathic short stature (ISS). J Clin Res Pediatr Endocrinol 2009;1:105-15.

19. Spiliotis BE, August GP, Hung W, Sonis W, Mendelson W, Bercu BB. Growth hormone neurosecretory dysfunction. A treatable cause of short stature. JAMA 1984;251:2223-30.

20. Aho CJ, Liu C, Zelman V, Couldwell WT, Weiss MH. Surgical outcomes in 118 patients with Rathke cleft cysts. J Neurosurg 2005;102:189-93.

21. Acharya SV, Gopal RA, Menon PS, Bandgar TR, Shah NS. Precocious puberty due to rathke cleft cyst in a child. Endocr Pract 2009; 15:134-7.

22. Hayashi Y, Tachibana O, Muramatsu N, Tsuchiya H, Tada M, Arakawa Y, et al. Rathke cleft cyst: MR and biomedical analysis of cyst content. J Comput Assist Tomogr 1999;23:34-8.

23. Nishioka H, Haraoka J, Izawa H, Ikeda Y. Magnetic resonance imaging, clinical manifestations, and management of Rathke's cleft cyst. Clin Endocrinol (Oxf) 2006;64:184-8.

24. Hama S, Arita K, Nishisaka T, Fukuhara T, Tominaga A, Sugiyama K, et al. Changes in the epithelium of Rathke cleft cyst associated with inflammation. J Neurosurg 2002;96:209-16.

25. Saeki N, Sunami K, Sugaya Y, Yamaura A. MRI findings and clinical manifestations in Rathke's cleft cyst. Acta Neurochir (Wien) 1999;141:1055-61.

26. Potts MB, Jahangiri A, Lamborn KR, Blevins LS, Kunwar S, Aghi MK. Suprasellar Rathke cleft cysts: clinical presentation and treatment outcomes. Neurosurgery 2011;69:1058-68. 